\title{
Study on Agricultural Modernization Based on the Perspective of WSR-Taking Jiangsu Province as an example

\author{
Yucheng Han
}

\author{
School of Economics and Management, Jiangsu University of Science and Technology, \\ Zhenjiang 212000, China \\ hunter2011@foxmail.com
}

\begin{abstract}
Keywords: Agricultural modernization, "wuli-shili-renli" systematical methodology, The evaluation of index system.
\end{abstract}

\begin{abstract}
Many cities of Jiangsu Province have been involved in agricultural modernization demonstration area. It is of great importance to analyze it's level of agricultural modernization. However, the design of index system of agricultural modernization still did not reflect concrete connotation of generalized agricultural modernization. The article expand the connotation of agricultural modernization from three aspects of wuli, shili, renli which is based on "wuli-shili-renli" systematical methodology. Then the author establishes the index system of agricultural modernization in Jiangsu Province. Agricultural modernization level will be obtained by comprehensive scoring method. The article highlights the basic role of physical factors of agricultural modernization as well as human factors throughout the evaluation process. The article also effectively solves the problem of too much emphasis on physical factors which is advantageous to the balanced development of agricultural modernization in three aspects.

"SAN Nong" problem (Agriculture, Rural areas and Farmers) is a focus of national attention, and agricultural modernization is its priority . In 1949, Premier Zhou Enlai has presented a proposal to develop modern agriculture and he gave a preliminary definition to the connotation of agricultural modernization in 1961. With the advancement of reform and opening up, the connotation has been constantly enriched [1]. Jiangsu Province is not only a major economic province but also an agricultural province. The arable land per capita in Jiangsu is $0.95 \mathrm{mu}$ which serve as an important reserve land. In addition, Jiangsu Province is known as "Land of Fish and Rice" due to the abundant water resources. ,Moreover, it has unique conditions for agricultural production and boasts rich crop varieties. After three expansions of the agricultural modernization demonstration zones, most cities in Jiangsu Province has been included within it. So the level of agricultural modernization in Jiangsu is of significance as a guide[2]. The agricultural modernization traditionally refers to agriculture in the narrow sense. However, agricultural modernization is not limited to it at this stage. The article discusses agricultural modernization refers to that in the broad sense, which is based on the perspective of the WSR - rural modernization(Wuli), agricultural modernization (Shili) and farmers modernization (Renli).
\end{abstract}

Agriculture, rural areas and farmers is a global and holistic concept. In order to promote agricultural modernization, we must coordinate the modernization of agriculture, rural areas and farmers development, otherwise it is not agricultural modernization in the true sense. At the same time, these three components of agricultural modernization should be analyzed separately according to the different roles they play in the operating mechanism. From the existing agricultural modernization index system, we can see that too much attention has been paid on index of Shili, that is, the agricultural production development level as well as the level of science and technology, but there is not enough emphasis on the rural modernization. In addition, the index system just focuses on the indicator of peasants' income. There has been a limitation in terms of the field examined. Therefore, an analysis of agricultural modernization based on the WSR highlights the importance of three aspects of development. For the modernization of agriculture it is of great theoretical and practical significance.

To accurately monitor the level of modernization in agriculture, we need a set of rational and holistic index system to quantify the level of modernization in agriculture. There is much 
controversy on the index system of agricultural modernization. Xu Xingming, and Yang Wanjiang (2000), Yi Jun, and Zhang Chunhua (2005) believe that modern agricultural production subsystem, rural industrialization and urbanization subsystems and subsystem level of rural society and economy and environment should be involved in the index system of agricultural modernization [3]. Fu Chen (2010), Xin Ling and Jiang Heping (2011) set up the index system from productivity, land productivity, input-output ratio, farmers ' income, the farmland under irrigation, mechanization, industrialization, business modernization, ecological aspects [4]. Zhang Shuying et al (2012) sets up the index system according to the five principles which are in the research ofThe study on the index system of agricultural modernization. The index system includes agricultural output, agricultural facilities and equipment, scientific and technological progress in agriculture, agricultural industry and agricultural support system[5]. In terms of current modernization index system, there are still some shortcomings, mainly in the following three areas: (1) there are too many indicators; (2) it is difficult to acquire some indicators' data. Some indicators cannot be obtained directly from the relevant statistical materials, which can only be obtained via complex calculations. (3) The index system pays too much attention on the level of agricultural production and development. Rural modernization and farmer's life is ignored to a great extent. In response to these shortcomings, this article will set up an index system of agricultural modernization in Jiangsu Province based on three dimensions of wuli, shili and renli so that it will reflect the characteristic of being global and rational.

\section{The basic principle of WSR systematical methodology}

"Wuli-Shili-Renli" systematical methodology (WSR) is a traditional eastern philosophical methodology. The systematical methodology contains only "Wuli" and "Shili" two aspects at that time [6]. Since then, people gradually realized that human factora exist in many of the issues and American system engineering expert Li Yaozi proposed that "Renli" should be included[7]. The core of WSR systemetical methodology is to analyzi problems with a perspective of global thinking in Wuli,Shili,Renli. First, we should consider "Wuli" aspects, namely the objective existence of research objects and base installation which can be seen as hardware which works for soft system service. Second, we should consider "Shili" , namely how to use objective things and existing external conditions reasonably and come up with solutions for operating mechanism as well as legal regulations for service. To be specific, it refers to using modern technology and methods for improving efficiency as well as modernizing management concept; finally, an essential part of the methodology is "Renli" aspect. The impact of human on social issues work through socio-economic and operating mechanism including interpersonal communication and the coordination mechanisms govering people and things.

\section{The construction of index system of agricultural modernization based on WSR}

People thought that agricultural modernization simply means modernization of agriculture apartment in the past which is a narrow understanding.This article studies agricultural modernization in the broad sense[8]. The agricultural modernization in the broad sense based on WSR is divided into three dimensions, "Wuli" refers to rural modernization;"Shili" refers to agriculture modernization; "Renli" refers to farmers'modernization. Specific content is as follows:

Wuli-rural modernization. First of all, It is essential for the ecological environment in rural areas. Arable land and water are the foundation of agriculture. Soil and water resources need to be protected while the use of chemical fertilizers, pesticides and plastic sheeting and other environmental pollution need to be reduced. Secondly, rural transportation, communications, housing, medical facilities and other infrastructure improvement are important indicators to narrow the gap between urban and rural areas[9]. Thirdly, the level of rural community as well as the efficiency of service in village committes are the necessary conditions determining whether rural areas are suitable for inhabitants. Finally, the life and the production of pollution need to be processed in a timely manner in order to maintain a sustainable development of agriculture. In 
summary, the special nature of the agricultural production in agricultural production needs "the modernization of the countryside".

Shili-the modernization of agriculture. This refers to the agricultural modernization in the narrow sense. It means that we usemodern industrial products and advanced science and technology in agricultural production which is complemented by a scientific management approach in order to increase productivity and resource utilization rate and specifically maximize agricultural output, mechanical level, electric level and government support, etc.

Renli-farmers' modernization. People is the most proactive form of productivity. It requires workers to be equipped with basis quality, professional skills, concepts of modern market economy and legal ethics in line with the needs of modern agricultural development advanced management method and system of science and technology in production, [10]. In addition to the concerns of farmers in production quality, the improvement in farmers ' material life, spiritual life, ways of thinking are the embodiment of the modernization of farmers.

The details have a shown in Fig. 1:

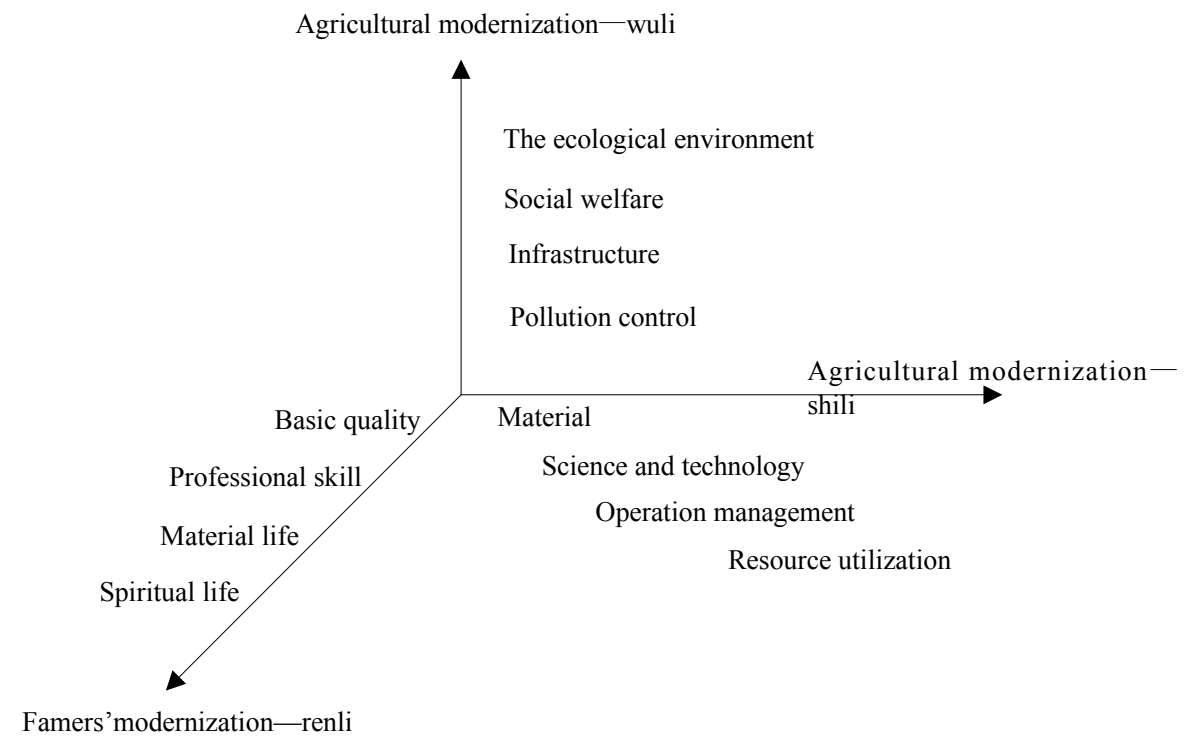

Fig. 1 WSR connotation of in the practice of the modernization of agriculture

To sum up, this article will set up an index system based on three dimensions of the WSR which will be shown in the following table (table 1) below:

Table 1 index system of agricultural modernization in China

\begin{tabular}{|c|c|c|c|c|}
\hline Dimensions & $\begin{array}{c}\text { First } \\
\text { indicators }\end{array}$ & Secondary indexes & $\begin{array}{l}\text { Target } \\
\text { value }\end{array}$ & $\begin{array}{l}\text { Realization } \\
\text { value }\end{array}$ \\
\hline \multirow{7}{*}{$\begin{array}{l}\text { wuli } \mathrm{Y}_{1} \text { ( rural } \\
\text { modernization ) }\end{array}$} & \multirow{3}{*}{$\begin{array}{l}\mathrm{U}_{1} \\
\text { rural living } \\
\text { environment }\end{array}$} & $\begin{array}{l}\mathrm{u}_{11} \text { realization rate of public service of town or } \\
\text { regional agricultural system } \%\end{array}$ & 97.0 & 79.1 \\
\hline & & $\mathrm{u}_{12}$ urbanization rate $\%$ & 60.0 & 64.1 \\
\hline & & $\mathrm{u}_{13}$ coverage rate of rural information $\%$ & 75.0 & 52.7 \\
\hline & \multirow{4}{*}{$\begin{array}{l}\mathrm{U}_{2} \\
\text { rural ecological } \\
\text { environment }\end{array}$} & $\mathrm{u}_{21}$ forest coverage rate $\%$ & 24.0 & 21.9 \\
\hline & & $\mathrm{u}_{22}$ disaster rate of natural disasters $\%$ & 10.0 & 6.0 \\
\hline & & $\mathrm{u}_{23}$ high standard farmland share $\%$ & 60.0 & 46.5 \\
\hline & & $\begin{array}{l}\mathrm{u}_{24} \text { units of chemical fertilizer application in arable } \\
\text { land }(\mathrm{kg})\end{array}$ & 47.43 & 47.43 \\
\hline \multirow[b]{3}{*}{ shili } & $\begin{array}{c}\mathrm{U}_{3} \\
\text { agricultural output }\end{array}$ & $\begin{array}{l}\mathrm{u}_{31} \text { agricultural added value of farming, forestry, } \\
\text { animal husbandry and fishery in every } \\
\text { unit(Yuan) }\end{array}$ & 3500.0 & 2896.8 \\
\hline & & $\mathrm{u}_{32}$ grain yield in an acre of land $(\mathrm{kg})$ & 450.0 & 425.7 \\
\hline & & $\begin{array}{l}\mathrm{u}_{41} \text { contribution rate of agricultural science and } \\
\text { technology progress } \%\end{array}$ & 70.0 & 63.2 \\
\hline
\end{tabular}




\begin{tabular}{|c|c|c|c|c|}
\hline \multirow[t]{2}{*}{$\begin{array}{l}\text { ( agricultural } \\
\text { modernization })\end{array}$} & $\begin{array}{l}\quad \mathrm{U}_{4} \\
\text { agricultural } \\
\text { technology } \\
\text { equipment }\end{array}$ & $\begin{array}{l}\mathrm{u}_{42} \text { agricultural mechanization level } \% \\
\mathrm{u}_{43} \text { water conservancy modernization level } \% \\
\mathrm{u}_{44} \text { food purchase and store modernization level } \%\end{array}$ & $\begin{array}{l}90.0 \\
90.0 \\
90.0\end{array}$ & $\begin{array}{l}78.0 \\
81.0 \\
48.3\end{array}$ \\
\hline & $\begin{array}{l}\mathrm{U}_{5} \\
\text { agricultural support }\end{array}$ & $\begin{array}{l}\mathrm{u}_{51} \text { transfer income per person of rural households } \\
\text { (Yuan) } \\
\mathrm{u}_{52} \text { agricultural insurance coverage } \%\end{array}$ & 1569.8 & 1513 \\
\hline \multirow{4}{*}{$\begin{array}{l}\text { renli } Y_{3} \text { ( famers' } \\
\text { modernization) }\end{array}$} & $\begin{array}{l}\mathrm{U}_{6} \\
\text { farmer's } \\
\text { standards }\end{array}$ & $\begin{array}{l}\mathrm{u}_{61} \text { net income of vevry farmer (Yuan) } \\
\mathrm{u}_{62} \text { compliance proportion of farmers ' income } \% \\
\mathrm{u}_{63} \text { Engel's coefficient of rural areas } \%\end{array}$ & $\begin{array}{l}32000.0 \\
50.0 \\
35.0\end{array}$ & $\begin{array}{l}12209.0 \\
5.1 \\
36.3\end{array}$ \\
\hline & \multirow{3}{*}{$\begin{array}{l}\mathrm{U}_{7} \\
\text { farmers' } \\
\text { quality }\end{array}$} & $\begin{array}{l}\mathrm{u}_{71} \text { the cultivated degree of new professional } \\
\text { farmers } \% \\
\mathrm{u}_{72} \text { proportion of farmers ' participating in } \\
\text { professional cooperatives } \%\end{array}$ & 80.0 & 19.0 \\
\hline & & $\begin{array}{l}\mathrm{u}_{73} \text { share of scale operation of the new agricultural } \\
\text { management operator }\end{array}$ & 60.0 & 39.6 \\
\hline & & $\begin{array}{l}\mathrm{u}_{74} \text { proportion of agriculturalists in the agricultural } \\
\text { labour force } \%\end{array}$ & 10.0 & 0.5 \\
\hline
\end{tabular}

Note: the actual values of indicators is taken from Jiangsu Provincial Bureau, the provincial Council and the National Bureau of Statistics survey in 2013, the target value is taken from the standard of the basic realization of modernization in our country and the statistical agencies of surveillance data.

\section{Measurement of agricultural modernization level in Jiangsu Province}

Determination of the index weight. We determine of the index weight by using hierarchy analysis method. Specific steps are as follows:

(1)Weigh of index structure. After analyzing the connotation of generalized agricultural modernization,we set up an index system of agricultural modernization based on wuli, shili and renli. Relevant factors are divided into four levels from top to bottom. They are the objective level-namely agricultural modernization in Jiangsu Province(u); dimensions level- wuli Y1, shili Y2 and renli Y3; guidelines level-the main indicators fromU1 to U7 and groups indicators from u11 to $\mathrm{u} 74$.

(2) Structure comparison matrix. First,we invite a number of experts to compare the groups index. Then,we judge the relative importance of each factor. Finally,we established judgment matrix. The judgment matrix commonly use 1-9 scales [11]. Based on this system, we form nine judgment matrixes.

(3)Consistency checking of judgment matrix. We can get eigenvalues according to the matrix theory of matrix. Then we use the variation of eigenvalue of judgment matrix to test consistent level of judgment. Steps are as follows:

We use equation $C I=\frac{\lambda_{\max }-n}{n-1}$ to check the consistency of decision makers' thought. The lager CI value is, the greater the degree of deviation from the consistency of judgement matrix will be. The smaller CI value is (close to 0 ), the better consistency of the judgment matrix will be.

We use RI values of the mean random consistency index of judgment matrix to judge the random consistency of the judgment matrix ratio $\mathrm{CR}$. When $C R=\frac{C I}{R I}<0.10$, the consistency of the judgment matrix is deemed satisfactory, or continue to adjust until satisfaction of the judgement matrix. Take subject index and its corresponding population index as an example, judgment matrix is constructed as follows: 
Table 2 Secondary index judgment matrix of agricultural modernization

\begin{tabular}{llll}
\hline $\mathrm{U}_{1}$ & $\mathrm{u}_{11}$ & $\mathrm{u}_{12}$ & $\mathrm{u}_{13}$ \\
\hline $\mathrm{u}_{11}$ & 1 & $1 / 3$ & 3 \\
$\mathrm{u}_{12}$ & 3 & 1 & 5 \\
$\mathrm{u}_{13}$ & $1 / 3$ & $1 / 5$ & 1
\end{tabular}

The calculation of matrix eigenvalues $=3.0385, \mathrm{CI}=0.0193, \mathrm{CR}=0.0332<0.10$ So the results satisfy the consistency check, $\mathrm{W}_{1}=\left(\mathrm{w}_{11}, \mathrm{w}_{12}, \mathrm{w}_{13}\right)=\left(\begin{array}{lll}0.2583 & 0.6370 & 0.1047\end{array}\right)$. Similarly to other weights of indicators: :

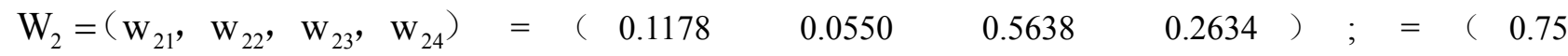
$0.25) ; \mathrm{W}_{4}=\left(\begin{array}{lllll}\mathrm{w}_{41}, & \mathrm{w}_{42}, & \mathrm{w}_{43}, & \mathrm{w}_{44}\end{array}\right)=\left(\begin{array}{llll}0.3 & 0.3 & 0.3 & 0.1\end{array}\right) ; \mathrm{W}_{5}=\left(\begin{array}{ll}\mathrm{w}_{51}, & \mathrm{w}_{52}\end{array}\right)=\left(\begin{array}{ll}0.1667 & 0.75\end{array}\right.$ $0.8333) ; \mathrm{W}_{6}=\left(\begin{array}{llll}\mathrm{w}_{61}, & \mathrm{w}_{62}, & \mathrm{w}_{63}\end{array}\right)=\left(\begin{array}{llll}0.6370 & 0.1047 & 0.2583\end{array}\right) ; \mathrm{W}_{7}=\left(\begin{array}{llll}\mathrm{w}_{71}, & \mathrm{w}_{72}, & \mathrm{w}_{73}, & \mathrm{w}_{74}\end{array}\right)=\left(\begin{array}{lll}0.125 & \end{array}\right.$ $\left.\begin{array}{lll}0.125 & 0.125 & 0.625\end{array}\right) ; \quad \mathrm{W}=\left(\mathrm{W}_{1}, \mathrm{~W}_{2}, \mathrm{~W}_{3}, \mathrm{~W}_{4}, \mathrm{~W}_{5}, \mathrm{~W}_{6}, \mathrm{~W}_{7}\right)=\left(\begin{array}{lllll}0.0725 & 0.0725 & 0.3171 & 0.3171\end{array}\right.$ $\left.\begin{array}{lll}0.1554 & 0.0327 & 0.0327\end{array}\right) ; Y_{1}=\left(y_{1}, y_{2}\right)=\left(\begin{array}{ll}0.1667 & 0.8333\end{array}\right) ; Y_{2}=\left(y_{3}, y_{4}, y_{5}\right)=\left(\begin{array}{ll}0.4286 & 0.4286\end{array}\right.$ $0.1428) ; Y_{3}=\left(y_{6}, y_{7}\right)=\left(\begin{array}{ll}0.25 & 0.75\end{array}\right)$

Data normalization. Due to the different indicators dimensions, the indicators need to be standardized which make them easier to analyze and compare. For the higher the number, the better the positive indicators, standardized calculation formula is:

$$
V_{k i}=\frac{X_{i}}{U_{i}}
$$

Among them, the $\mathrm{V}_{\mathrm{ki}}$ represents standardized value; $\mathrm{X}_{\mathrm{i}}$ represents the realization value of I-th index in K-th main index group ; $\mathrm{U}_{\mathrm{i}}$ represents the target value of I-th index in $\mathrm{k}$-th main index group.

For the lower the number, the better the negative indicators, standardized calculation formula is:

$$
V_{k i}=1-\frac{X_{i}-U_{i}}{X_{i}}
$$

Comprehensive scoring method of index system.(1) The composite score for each subject index:

$$
A=\sum_{i=1}^{m_{k}} W_{k i} V_{k i}
$$

Among them, A represents a composite score for each subject index; $\mathrm{W}_{\mathrm{ki}}$ represents the weight of I-th index in k-th subject index group; $\mathrm{V}_{\mathrm{ki}}$ represents the standardized value of I-th index in K-th subject index group; $\mathrm{M}_{\mathrm{K}}$ represents the number of $\mathrm{K}$-th subject index group.

(2) Total score of index system:

$$
Y=\sum_{k=1}^{n} W_{k} A_{k}
$$

Among them, $Y$ represents the total score of the index system of agricultural modernization in Jiangsu Province; $\mathrm{W}_{\mathrm{k}}$ represents the weight of main indicators relative to the standards level; $A_{k}$ represents composite score for each main indicator.

By the results of the model above, the result of agricultural modernization in Jiangsu Province are as follows: 
Table 3 results of evaluation index system of agricultural modernization in Jiangsu Province in 2013

\begin{tabular}{|c|c|c|c|c|}
\hline Level indicators & score & $\begin{array}{l}\text { WSR } \\
\text { category }\end{array}$ & perspective & score \\
\hline $\mathrm{U}_{1}$ rural living environment & 0.9212 & wuli & & 0.8725 \\
\hline $\mathrm{U}_{2}$ rural ecological environment & 0.8628 & & & \\
\hline $\mathrm{U}_{3}$ agricultural output & 0.8572 & shili & & 0.8722 \\
\hline $\begin{array}{l}\mathrm{U}_{4} \text { agricultural technology and } \\
\text { equipment }\end{array}$ & 0.8545 & & & \\
\hline $\mathrm{U}_{5}$ agricultural support & 0.9705 & & & \\
\hline $\mathrm{U}_{6}$ farmer's living standards & 0.5028 & renli & & 0.3124 \\
\hline $\mathrm{U}_{7}$ farmers' professional quality & 0.2489 & & & \\
\hline Comprehensive evaluation value & & 0.8475 & & \\
\hline
\end{tabular}

Analysis of evaluation results. The comprehensive evaluation value of agricultural modernization in Jiangsu province in 2013 is 0.8475 . According to the standard reference level of agricultural modernization, agricultural modernization has been basically achieved in Jiangsu Province and socio-economic conditions and material base has been sufficient for promoting agricultural modernization.

We can clearly see from table 3 that index of Renli has the lowest score which only reaches $35.8 \%$ of the indicators of wuli and renli. It lags behind in the country. The low score of these indicators because there is a huge gap between farmers ' living standard and quality and target of agricultural modernization. In terms of farmers ' living standards, farmers ' per capita income reaches only $10.2 \%$. This has many reasons such as limited arable land, too many people participating in primary industry and rising costs of agricultural production. In addition, it is not enough to gain a high profit only by selling raw material. In terms of farmers ' professional quality, the number of agricultural skilled workers only occupies $5 \%$ of the agricultural labour force's target value. So it is grossly inadequate in quantity and quality. Farmers are risk-averters especially in the case of single farmers' autonomous operation. Huge obstacles exist in the promotion of agricultural technology. In addition, due to the low overall quality of farmers and the lack of attention paid to the agricultural technology which is not enough for agricultural technology demand, the current agricultural technology promotion still rely on grass-roots agricultural technicians. The score of indicators of Wuli is higher than indicators of renli and comparable to indicators of shili. Among the environmental indicators of rural life, the coverage rate of rural informatization has the lowest score, thus the lowest rate reaches the standard. The reasons are as follows: First, infrastructure needed for rural information which is the foundation of rural modernization falls behind. . Secondly, there are problems in collecting capacity and the data processing capacity of agricultural sectors concerned. These problems not only reduce information practical value but also effect run efficiency. Last but not least, there are limitations in farmers due to themselves' culture quality. Farmers do not have a high demand for agricultural information and the information consciousness is weak. The score of indicators of rural ecological environment, chemical fertilizer application in arable land has remained high which is more than 1.93 times of safe upper limit[11]. Score of indicators of Shili is higher. It means that the realization level of agricultural apartment's modernization of "San Nong" modernization is higher. However, among them, food purchase and storage modernization level is still low which only reaches $53.7 \%$. Upgrading food purchase and storage level includes the ability to raise grain purchase, reserve levels, storage levels, Internet of grain depot construction and supervision of grain quality. In addition, the realization rate of value added in agricultural farming, forestry, animal husbandry and fishery as well as agricultural mechanization level of compliance is lower than $90 \%$. 


\section{Conclusion}

This paper describes the connotation of agricultural modernization in the broad sense under the new situation and establishes index system of agricultural modernization in China from three dimensions based on WSR perspective. So it has a certain legitimacy and wholeness. Empirical study on the combination of theory and practice, the artitle has a certain universality and representation. From the measurment of agricultural modernization in Jiangsu Province in 2013, we can see that the indicators of shili and wuli achieved the similar degree. However, indicators of renli gets the lowest score.

From the perspective of Renli, in order to improve the farmers ' per capita income, first we should speed up the development of agro-processing industries so that we can increase profit margins. Secondly, we should reduce costs hich keep on rising by using technology to increase unit production. Finally, we should encourage flows of workers in primary industry in China to second or thied industries so that farmers' income will be increased [12]. At the same time, the rural Engel's coefficient will be further reduced. It is beneficial for farmers to live a happy life. To increase the number of agricultural skilled workers, which is necessary to increase their welfare. To solve the problem of their work expenditure and medical treatment is required so that they can devote to their job and the number of agricultural technicians will increase. In terms of quality, personnel training and knowledge update should also be included in the government budget. We should form a better training system, update management mode, get rid of the tradition concept of education and introduce talents with practical experience. From the perspective of wuli, in order to improve the coverage rate of rural informatization, first of all we should strengthen the construction of agricultural infrastructure. Secondly we should enhance information processing capacity and establish informationization system platform. In addition, we should introduce talents both skilled in agricultural and information technology and lead farmers to learn network and prompt Internet using in rural areas directly. Finally, fertilizer should be reduced and the utilization of organic fertilizer should be improved in pursuit of the zero growth of main crop fertilizer in 2020. From the perspective of Shili, we need to increase the gross output value of farming, forestry, animal husbandry and fishery and at the same time reduce consumption. The way to increase gross output include stabling grain acreage, optimizing crop structure and increasing unit yield and so on. Reducing intermediate consumption includes reducing labour costs, government tax cuts and subsidy increase. In order to solve the problem of low levels of agricultural mechanization, first we should upgrade agricultural machinery speed up the production of reliable and easy-operating heavy machinery. In addition,demonstration bases of agricultural mechanization should be established in order to guide the farmers to use advanced and suitable agricultural machinery. So that we can increase agricultural productivity and intensive level.

To achieve the balanced development of "San Nong" modernization, efforts must be made to speed up the construction of rural modernization and farmer's modernization so that we can realize the agricultural modernization soon.

\section{References}

[1] H.P. Jiang, K. Cui. The construction and evaluation of Index system of agricultural modernization in China's main grain-producing area. Study on the modernization of agriculture, 2011,06:646-651.

[2] X.Q. Liu, S.M. Li. Characteristics and developing trend of agricultural modernization. Modernization of agriculture, 2013,04:42-44.

[3] J.Z. Ye, W.J. Wang. Discipline of agricultural: reflections on modern agricultural technology. China rural survey, 2013,02:2-10+93. 
[4] J.F. Gu, X.J. Tang, Z.X. Zhu. Survey of wuli-shili-renli system methodology. Transportation engineering and information 2007,06:51-60.

[5] H.J. Wang. Study on the audit and control of the risks of university management information system -based on WSR methodology and COBIT theory. Auditing and economic research, 2014,05:23-30.

[6] X.J. Wang, Y. Zhang. Non-uniform of gray correlation based on AHP and DEA methods. Theory and practice of systems engineering, 2011,07:1222-1229.

[7] C.Y. Jiang. Changes in the growth of farmers ' income in China. China's rural economy, 2008,09:4-12.

[8] X.S. Zhou, Y. Liu. Chinese farmers ' income structure evolution and its implications. Chinese Agricultural Science Bulletin, 2012,14:210-213.

[9] R.Q. Liu. A new perspective on balancing urban and rural development: reform of rural housing property rights. Economic reform, 2006,02:114-118

[10] H.B. Zhu. Analysis of characteristics and influencing factors of Chinese cultivated land resources ecological security. Study on the modernization of agriculture, 2008,02:194-197.

[11] J.H. Liu. The status and development trend of agricultural mechanization in China. Beijing agriculture, 2012,03:202-203.

[12] Y.N. Zhao, T.Y. You, X. Zhao, D.G. Hu. The analysis of the government's agricultural mechanization investment: taking Hubei Province as the example. Agricultural technology economy, 2014,05:67-73. 